\title{
Emergent constraints on projections of declining primary production in the tropical oceans
}

\author{
Lester Kwiatkowski ${ }^{1 *}$, Laurent Bopp ${ }^{1,2}$, Olivier Aumont ${ }^{3}$, Philippe Ciais ${ }^{1}$, Peter M. Cox ${ }^{4}$, Charlotte \\ Laufkötter $^{5}$, Yue Li ${ }^{6}$, Roland Seferian ${ }^{7}$ \\ ${ }^{1}$ Laboratoire des Sciences du Climat et de l'Environnement (LSCE), IPSL, CEA/CNRS/UVSQ, Orme des \\ Merisiers, Gif-sur-Yvette, 91190, France; \\ ${ }^{2}$ Laboratoire de Météorologie Dynamique (LMD/IPSL), CNRS/Ecole Normale Supérieure, 24 rue \\ Lhomond, 75231 Paris Cedex 05, France; \\ ${ }^{3}$ Laboratoire d'Océanographie et de Climatologie: Expérimentation et Approches Numériques (LOCEAN), \\ IPSL, CNRS/UPMC/IRD/MNHN, 4 Place Jussieu, 75005 Paris, France; \\ ${ }^{4}$ College of Engineering, Mathematics and Physical Sciences, University of Exeter, Exeter EX4 4QF, UK; \\ ${ }^{5}$ NOAA/Geophysical Fluid Dynamics Laboratory, Princeton University, Princeton, New Jersey, USA; \\ ${ }^{6}$ Sino-French Institute for Earth System Science, College of Urban and Environmental Sciences, Peking \\ University, Beijing, 100871, China; \\ ${ }^{7}$ Centre National de Recherches Météorologiques-Groupe d'Etude de l'Atmosphère \\ Météorologique/Groupe de Météorologie de Grande Echelle et Climat, 31100 Toulouse, France.
}

\author{
*Lester Kwiatkowski \\ Laboratoire des Sciences du Climat et de l'Environnement (LSCE) \\ CEA-Orme des Merisiers \\ 91190 \\ Gif-sur-Yvette \\ France \\ Lester.Kwiatkowski@Isce.ipsl.fr
}


Marine primary production is a fundamental component of the Earth System, providing the main source of food and energy to the marine food web, and influencing the concentration of atmospheric $\mathrm{CO}_{2}{ }^{1,2}$. Earth System Model (ESM) projections of global marine primary production are highly uncertain with models projecting both increases ${ }^{3,4}$ and declines of up to $20 \%$ by $2100^{5,6}$. This uncertainty is predominantly driven by the sensitivity of tropical ocean primary production to climate change, with the latest ESMs suggesting $21^{\text {st }}$ century tropical declines of between 1 and $30 \%^{5,6}$. Here we identify an emergent relationship ${ }^{7,8,9,10,11}$ between the long-term sensitivity of tropical ocean primary production to rising equatorial zone sea surface temperature (SST) and the interannual sensitivity of primary production to EI Niño/Southern Oscillation (ENSO) driven SST anomalies. Satellite based observations of the ENSO sensitivity of tropical primary production are then used to constrain projections of the long-term climate impact on primary production. We estimate that tropical primary production will decline by $3 \pm 1 \%$ per kelvin increase in equatorial zone SST. Under a business-as-usual emissions scenario this results in an $11 \pm 6 \%$ decline in tropical marine primary production and a $6 \pm 3 \%$ decline in global marine primary production by 2100 .

Net primary production (NPP) by marine phytoplankton is responsible for approximately $50 \%$ of global biological carbon fixation ${ }^{12,13}$ and a key determinant of atmospheric $\mathrm{CO}_{2}$ concentrations ${ }^{2}$. With a turnover time of approximately 1 week $^{14}$ phytoplankton are also the base of the marine food web, controlling the energy and food available to higher tropic levels and ultimately fisheries ${ }^{1,15,16}$.

Ocean NPP is tightly coupled to climate variability on seasonal and interannual timescales, as shown by observations ${ }^{17,18,19}$ and reproduced by models ${ }^{5}$. This is particularly the case in the permanently stratified tropical oceans where there is a strong relationship between El Niño/Southern Oscillation (ENSO) variability and primary production ${ }^{17,20}$. In ENSO positive phases, a reduction in upwelling intensity and an increase in thermal stratification typically reduces the input of nutrients from nutrient-rich deeper waters to nutrient depleted surface waters. As phytoplankton production in the euphotic zone is highly dependent on nutrient availability, increased stratification during warmer conditions suppresses primary production ${ }^{17,20}$ (Fig. 1). This interannual coupling between ENSO variability and tropical ocean NPP is predominately driven by the Pacific ${ }^{18}$. In other regions coupling between stratification and NPP appears limited by concurrent changes in the advective supply of nutrients and the wind and buoyancy forcing available to overturn the water column to the nutricline ${ }^{19}$.

There are large uncertainties associated with observations of NPP that predate satellite remote sensing, with no consensus on century-scale global trends. Satellite observations since 1997 have shown that tropical NPP fluctuations have a strong inverse relationship with SST anomalies ${ }^{17}$, however the satellite record is too short to separate natural variability from trends caused by anthropogenic climate change ${ }^{21,22}$.

In order to assess the impact of climate change on NPP, a variety of ocean biogeochemistry models of wide-ranging complexity have been developed, and are now integral components of Earth System Models (ESMs) ${ }^{23}$. Previous generation models projected global ocean primary production would decline $2-20 \%$ over the $21^{\text {st }}$ century under the Special Report on Emissions Scenario A2 (SRES A2) baseline ${ }^{5}$. Current generation ESMs, which typically include more complete ocean biogeochemistry descriptions, 
still project a wide range of global ocean primary production changes within the $21^{\text {st }}$ century ${ }^{6}$. Under the business-as-usual Representative Concentration Pathway 8.5 (RCP8.5) scenario ${ }^{24}$, models project global NPP declines of $0-20 \%$ in the 2090 s relative to $1990 s^{6}$ (Fig. S1). Projected global declines are driven by reductions in NPP in the equatorial and sub tropical biomes ${ }^{25}$ due to stratification-driven reductions in nutrient availability as well as increases in grazing and other phytoplankton loss processes ${ }^{4}$. These reductions are slightly compensated for by increases in NPP at high latitudes ${ }^{4,25}$.

The current uncertainty associated with future NPP changes is larger across ESM ensembles than across different scenarios of climate chang $e^{6,25,26}$. Constraining estimates of the climate sensitivity of tropical ocean primary production is one of the major challenges in understanding how the ocean carbon cycle and marine food web will respond to future climate change ${ }^{4}$.

The use of emergent inter-model relationships in conjunction with observational constraints is one of the recent advances in reducing the uncertainty of climate projections ${ }^{7,8,9,10,11}$. Emergent inter-model relationships relate the long-timescale climate sensitivity of a given variable to the sensitivity to shorttimescale variability or trend of the same or a related variable, across a multi-model ensemble.

Observations of the short timescale sensitivity can then be applied to the emergent relationship to infer a constrained long-timescale sensitivity of the variable of interest. Such techniques have been used to reduce uncertainty in projections of Arctic summer sea ice ${ }^{7,8}$ and terrestrial tropical carbon fluxes ${ }^{9,10}$.

Utilising the Coupled Model Intercomparison Project Phase 5 (CMIP5) ESM ensemble (Table S1), we identify an emergent relationship between the interannual sensitivity of tropical $\left(30^{\circ} \mathrm{N}-30^{\circ} \mathrm{S}\right)$ marine NPP to ENSO driven SST anomalies in the Niño 3.4 equatorial zone region $\left(5^{\circ} \mathrm{N}-5^{\circ} \mathrm{S}, 120^{\circ} \mathrm{W}-170^{\circ} \mathrm{W}\right)$ and the long-term sensitivity of tropical marine NPP to climate change driven SST anomalies in the Niño 3.4 region. In defining tropical NPP sensitivity relative to Niño 3.4 region SST anomalies, intrinsic ENSO climate variability, which is highly variable across the ESM ensemble, is accounted for.

The existence of such an emergent relationship implies that, for a given model, the response of tropical NPP to long-term climate change is governed by similar processes to those that determine the interannual sensitivity of NPP to ENSO variability. It does not require that all models have the same dominant mechanisms. Indeed, for certain models the dominant mechanism controlling interannual and long-term NPP sensitivity is nutrient limitation while in other models it appears to be zooplankton grazing and other phytoplankton loss terms ${ }^{4}$ (Fig. S2).

The sensitivity of tropical NPP to ENSO variability was diagnosed for each model from the last 200 years of pre-industrial control simulations as the linear regression coefficient between Niño 3.4 region SST anomalies and tropical NPP anomalies. All the models exhibit a negative relationship $(P<0.02)$ between SST anomalies in the ENSO driven Niño 3.4 region and anomalies in tropical NPP (Fig. 2a, S3). NPP declines are typically driven by reductions in NPP in the central and eastern tropical Pacific and in certain models offset by increases in NPP in the western Pacific and eastern Indian Ocean (Fig. S4).

The long-term climate impact on NPP was diagnosed from RCP8.5 simulations as the decline in tropical NPP relative to $1990-2000$ values, per degree of Niño 3.4 region SST warming. This was calculated for 
each model as the linear regression coefficient between NPP and SST anomalies with all models exhibiting inverse relationships ( $P<0.001$; Fig. 2b, S5).

Across the multi-model ensemble there is a strong positive correlation $(r=0.91, P<0.001)$ between the interannual sensitivity of tropical NPP to ENSO driven SST variability and the long-term sensitivity of tropical NPP to climate change in the $21^{\text {st }}$ century (Fig. 3). Models with higher interannual NPP sensitivity to SST anomalies in pre-industrial simulations consistently project greater declines in tropical NPP per degree warming in the $21^{\text {st }}$ century (Fig. 3).

Marine NPP, unlike chlorophyll concentrations, cannot be directly measured from space. Consequently multiple products of NPP that use satellite chlorophyll and incident light data, in combination with descriptions of phytoplankton physiology have been developed ${ }^{27}$. Given that these NPP products can have large discrepancies ${ }^{27}$, we derive observational constraints from four algorithms over the Seaviewing Wide Field-of-View Sensor (SeaWIFS) satellite record (Fig. 2a, S6): the Vertically Generalised Production Model (VGPM) ${ }^{14}$, the Carbon-based Production Model (CbPM) ${ }^{28}$, the Marra et al. 2003 model $(\text { Marra) })^{29}$ and the Carr et al. 2002 model (Carr) ${ }^{30}$. Observational constraints on the interannual sensitivity of tropical NPP to Niño 3.4 region SST anomalies were calculated as the linear regression coefficient between each NPP algorithm and the contemporaneous Hadley Centre Sea Ice and Sea Surface Temperature data $\operatorname{set}^{31}$ (HadISST1). The resulting constraints are $-3.2 \pm 1.3,-2.8 \pm 0.9,-1.5 \pm 0.4$ and $2.1 \pm 0.6 \% \mathrm{~K}^{-1}$ (standard errors) for the VGPM, CbPM, Marra and Carr algorithms over the period 19982008, respectively.

Applying the observational constraints to the multi-model emergent relationship leads us to infer estimates of the long-term sensitivity of tropical primary production to future Niño 3.4 region SST warming of between $-3.4 \pm 1.3 \% \mathrm{~K}^{-1}$ (VGPM) and $-2.4 \pm 1.1 \% \mathrm{~K}^{-1}$ (Marra). There is therefore close agreement between the observational constraints, all of which substantially reduce the uncertainty relative to the unconstrained ensemble PDF $\left(-4.0 \pm 2.2 \% \mathrm{~K}^{-1}\right.$; Fig. 3b). The application of observational constraints greatly reduces the probability that declines in long-term NPP will exceed $6 \% \mathrm{~K}^{-1}$. In the unconstrained ensemble this has a probability of $18 \%$. This is reduced to $<1.8 \%$ for all observational constraints. Although no individual model predicts a positive long-term climate impact on tropical NPP $\left(>0 \% \mathrm{~K}^{-1}\right)$, this has an unconstrained probability of $3.5 \%$ and has been projected in other studies ${ }^{4,3}$. This probability is reduced to $<1.5 \%$ when all four constraints are applied. Given the multi-model mean RCP8.5 Niño 3.4 region SST anomaly is $3.9 \pm 1.3 \mathrm{~K}$ in 2100 relative to the $1990 \mathrm{~s}$, our emergent constraints imply a $21^{\text {st }}$ century tropical NPP decline of between $13.0 \pm 6.5 \%$ (VGPM constraint) and $9.3 \pm 5.1 \%$ (Marra constraint) under this business-as-usual scenario.

As the CMIP5 projections of global NPP decline are predominantly driven by changes in the tropical oceans ${ }^{4,6,25}$, constraints on the sensitivity of tropical NPP can also be used to reduce the uncertainty associated with the long-term sensitivity of global NPP (Fig. S8). The unconstrained global NPP sensitivity is $-2.3 \pm 1.2 \%$ per kelvin increase in Niño 3.4 region SST anomaly while the constrained estimates are between $-1.9 \pm 0.7 \% \mathrm{~K}^{-1}$ and $-1.4 \pm 0.6 \% \mathrm{~K}^{-1}$ (Fig. S8). Given the multi-model mean Niño 3.4 region SST anomaly of $3.9 \pm 1.3 \mathrm{~K}$, this implies a $21^{\text {st }}$ century global NPP decline of between $7.0 \pm 3.4 \%$ (VGPM constraint) and $5.4 \pm 3.0 \%$ (Marra constraint) under the RCP8.5 scenario. 
Although the emergent constraints on tropical NPP are robust for RCP8.5, alternative scenario processes could influence the slope of the multi-model emergent relationship and therefore the constraints. In particular, the extent of future natural and anthropogenic nutrient deposition and transient enhancement of deep ocean mixing under certain climate mitigation scenarios ${ }^{32}$.

Our analysis highlights the need to reconcile the apparent differences between the mechanisms driving NPP sensitivities in different $\mathrm{ESMs}^{4}$ (Fig. S2). This will require future multi-model intercomparison projects to provide phytoplankton growth rates and loss terms in addition to NPP so that the relative contribution of bottom-up and top-down limitation can be assessed throughout the photic zone and ensured consistent with observations.

Future refinements of emergent constraints on NPP projections will require more expansive ESM ensembles as well as longer satellite chlorophyll records that encompass multiple large-scale ENSO events. There is also a need to consolidate the diverse array of NPP algorithms and ensure that they provide accurate descriptions of photoacclimation so that NPP estimates are reliable ${ }^{33}$.

Emergent constraints on tropical marine primary production projections substantially increase our confidence that rising SSTs will result in a long-term decrease in tropical NPP throughout the $21^{\text {st }}$ century while simultaneously reducing the probability of the most extreme projections of tropical NPP decline. Given that marine primary production is the ultimate control on the energy available to the marine food web $^{15,16}$, tropical NPP declines may have cascading and potentially amplified impacts on higher trophic levels, and on the goods and services they provide ${ }^{34}$. More accurate projections of declining tropical NPP may also prove useful for a better ecosystem-based management of fisheries across the tropical oceans. 


\section{References}

1. Chassot, E. et al. Global marine primary production constrains fisheries catches. Ecol. Lett. 13, 495-505 (2010).

2. Volk, T. \& Hoffert, M. I. in The Carbon Cycle and Atmospheric CO2: Natural Variations Archean to Present (eds. Sundquist, E. T. \& Broecker, W. S.) 99-110 (American Geophysical Union, 1985).

3. Taucher, J. \& Oschlies, A. Can we predict the direction of marine primary production change under global warming? Geophys. Res. Lett. 38, L02603 (2011).

4. Laufkötter, C. et al. Drivers and uncertainties of future global marine primary production in marine ecosystem models. Biogeosciences 12, 6955-6984 (2015).

5. Steinacher, M. et al. Projected 21st century decrease in marine productivity: a multi-model analysis. Biogeosciences 7, 979-1005 (2010).

6. Bopp, L. et al. Multiple stressors of ocean ecosystems in the 21st century: projections with CMIP5 models. Biogeosciences 10, 6225-6245 (2013).

7. Hall, A. \& Qu, X. Using the current seasonal cycle to constrain snow albedo feedback in future climate change. Geophys. Res. Lett. 33, L03502 (2006).

8. Boé, J., Hall, A. \& Qu, X. September sea-ice cover in the Arctic Ocean projected to vanish by 2100. Nat. Geosci. 2, 341-343 (2009).

9. Cox, P. M. et al. Sensitivity of tropical carbon to climate change constrained by carbon dioxide variability. Nature 494, 341-344 (2013).

10. Wenzel, S., Cox, P. M., Eyring, V. \& Friedlingstein, P. Projected land photosynthesis constrained by changes in the seasonal cycle of atmospheric CO2. Nature 538, 499-501 (2016).

11. Allen, M. R. \& Ingram, W. J. Constraints on future changes in climate and the hydrologic cycle. Nature 419, 224-232 (2002).

12. Field, C. B., Behrenfeld, M. J., Randerson, J. T. \& Falkowski, P. Primary Production of the Biosphere: Integrating Terrestrial and Oceanic Components. Science 281, 237-240 (1998).

13. Falkowski, P. G., Barber, R. T. \& Smetacek, V. Biogeochemical Controls and Feedbacks on Ocean Primary Production. Science 281, 200-206 (1998).

14. Behrenfeld, M. J. \& Falkowski, P. G. Photosynthetic rates derived from satellite-based chlorophyll concentration. Limnol. Oceanogr. 42, 1-20 (1997).

15. Pauly, D. \& Christensen, V. Primary production required to sustain global fisheries. Nature 374, 255-257 (1995). 
16. Friedland, K. D. et al. Pathways between Primary Production and Fisheries Yields of Large Marine Ecosystems. PLOS ONE 7, e28945 (2012).

17. Behrenfeld, M. J. et al. Climate-driven trends in contemporary ocean productivity. Nature 444, 752-755 (2006).

18. Dave, A. C. \& Lozier, M. S. Examining the global record of interannual variability in stratification and marine productivity in the low-latitude and mid-latitude ocean. J. Geophys. Res. Oceans 118, 31143127 (2013).

19. Lozier, M. S., Dave, A. C., Palter, J. B., Gerber, L. M. \& Barber, R. T. On the relationship between stratification and primary productivity in the North Atlantic. Geophys. Res. Lett. 38, L18609 (2011).

20. Behrenfeld, M. J. et al. Biospheric Primary Production During an ENSO Transition. Science 291, 2594-2597 (2001).

21. Gregg, W. W., Conkright, M. E., Ginoux, P., O’Reilly, J. E. \& Casey, N. W. Ocean primary production and climate: Global decadal changes. Geophys. Res. Lett. 30, 1809 (2003).

22. Wernand, M. R., Woerd, H. J. van der \& Gieskes, W. W. C. Trends in Ocean Colour and Chlorophyll Concentration from 1889 to 2000, Worldwide. PLOS ONE 8, e63766 (2013).

23. Kwiatkowski, L. et al. iMarNet: an ocean biogeochemistry model intercomparison project within a common physical ocean modelling framework. Biogeosciences 11, 7291-7304 (2014).

24. Riahi, K. et al. RCP 8.5-A scenario of comparatively high greenhouse gas emissions. Clim. Change 109, 33-57 (2011).

25. Cabré, A., Marinov, I. \& Leung, S. Consistent global responses of marine ecosystems to future climate change across the IPCC AR5 earth system models. Clim. Dyn. 45, 1253-1280 (2014).

26. Frölicher, T. L., Rodgers, K. B., Stock, C. \& Cheung, W. W. L. Sources of uncertainties in 21st century projections of potential ocean ecosystem stressors. Glob. Biogeochem. Cycles 2015GB005338 (2016). doi:10.1002/2015GB005338

27. Carr, M.-E. et al. A comparison of global estimates of marine primary production from ocean color. Deep Sea Res. Part II Top. Stud. Oceanogr. 53, 741-770 (2006).

28. Behrenfeld, M. J., Boss, E., Siegel, D. A. \& Shea, D. M. Carbon-based ocean productivity and phytoplankton physiology from space. Glob. Biogeochem. Cycles 19, GB1006 (2005).

29. Marra, J., Ho, C. \& Trees, C. C. An Alternative Algorithm for the Calculation of Primary Productivity from Remote Sensing Data. (Lamont-Doherty Earth Observatory, 2003).

30. Carr, M.-E. Estimation of potential productivity in Eastern Boundary Currents using remote sensing. Deep Sea Res. Part II Top. Stud. Oceanogr. 49, 59-80 (2002). 
31. Rayner, N. A. et al. Global analyses of sea surface temperature, sea ice, and night marine air temperature since the late nineteenth century. J. Geophys. Res. Atmospheres 108, 4407 (2003).

32. John, J. G., Stock, C. A. \& Dunne, J. P. A more productive, but different, ocean after mitigation. Geophys. Res. Lett. 42, 2015GL066160 (2015).

33. Behrenfeld, M. J. et al. Revaluating ocean warming impacts on global phytoplankton. Nat. Clim. Change 6, 323-330 (2016).

34. Barber, R. T. \& Chávez, F. P. Ocean variability in relation to living resources during the 1982-83 El Niño. Nature 319, 279-285 (1986).

\section{Acknowledgements}

This study was funded by the ERC IMBALANCE-P synergy grant (ref 610028) and the H2020 CRESCENDO grant (ref 641816). We acknowledge the World Climate Research Programme's Working Group on Coupled Modelling, which is responsible for CMIP. For CMIP the US Department of Energy's Program for Climate Model Diagnosis and Intercomparison provided coordinating support and led the development of software infrastructure in partnership with the Global Organisation for Earth System Science Portals. To analyse the CMIP5 data, this study benefited from the IPSL Prodiguer-Ciclad facility which is supported by CNRS, UPMC, Labex L-IPSL which is funded by the ANR (ref ANR-10-LABX-0018) and by the European FP7 IS-ENES2 project (ref 312979).

\section{Author Contributions}

L.K. and L.B. led the study. R.S. provided observational data. C.L. and P.M.C. provided analytical assistance. All co-authors contributed to the manuscript.

\section{Author information}

The authors declare no competing financial interests. Correspondence and requests for materials should be addressed to L.K. 
Figures

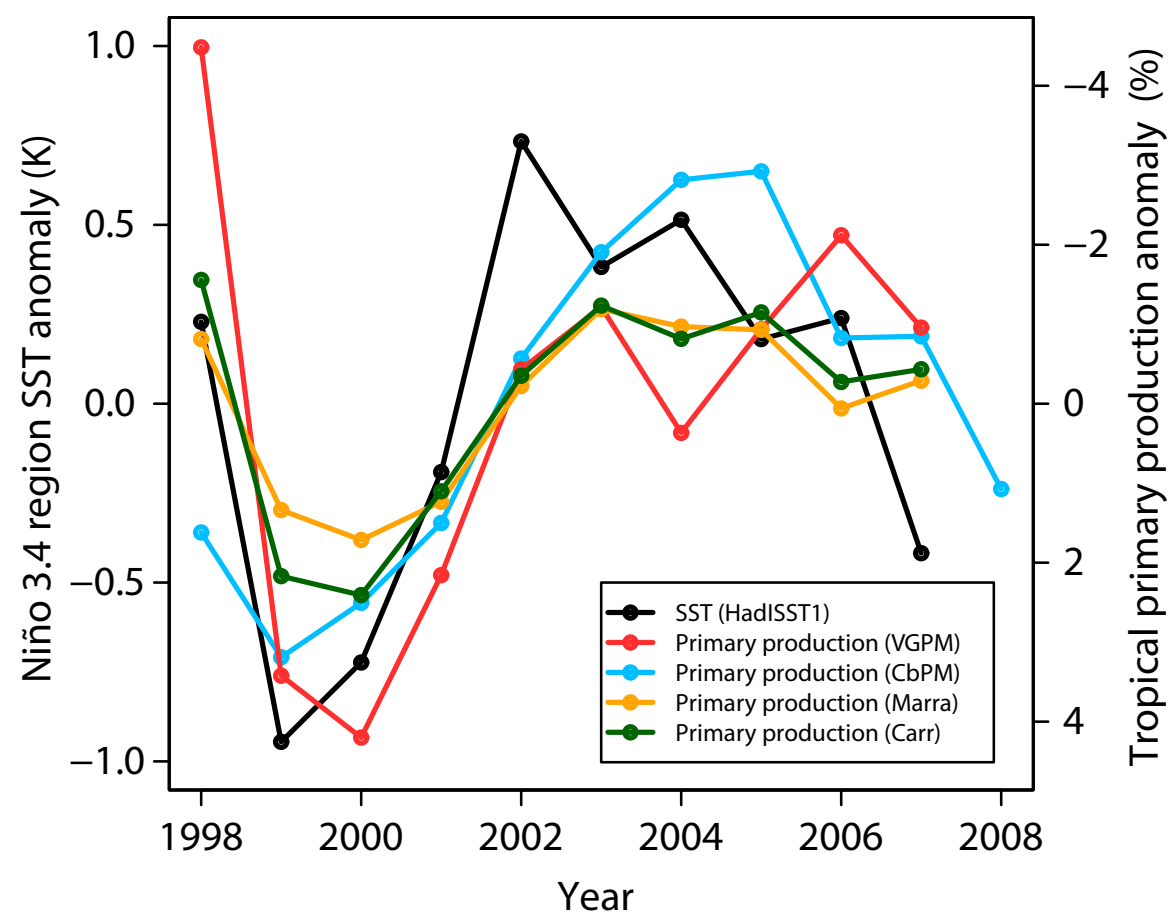

Figure 1. The observed sensitivity of tropical primary production to Niño 3.4 region SST anomalies.

Niño 3.4 region $\left(5^{\circ} \mathrm{N}-5^{\circ} \mathrm{S}, 170^{\circ}-120^{\circ} \mathrm{W}\right)$ HadISST1 SST anomalies and tropical $\left(30^{\circ} \mathrm{N}-30^{\circ} \mathrm{S}\right)$ primary production anomalies during the SeaWIFS satellite record. Primary production estimates are shown for the Vertically Generalised Production Model (VGPM; red), the Carbon-based Production Model (CbPM; blue), the Marra et al. 2003 model (Marra; orange) and the Carr et al. 2002 model (Carr; green). 

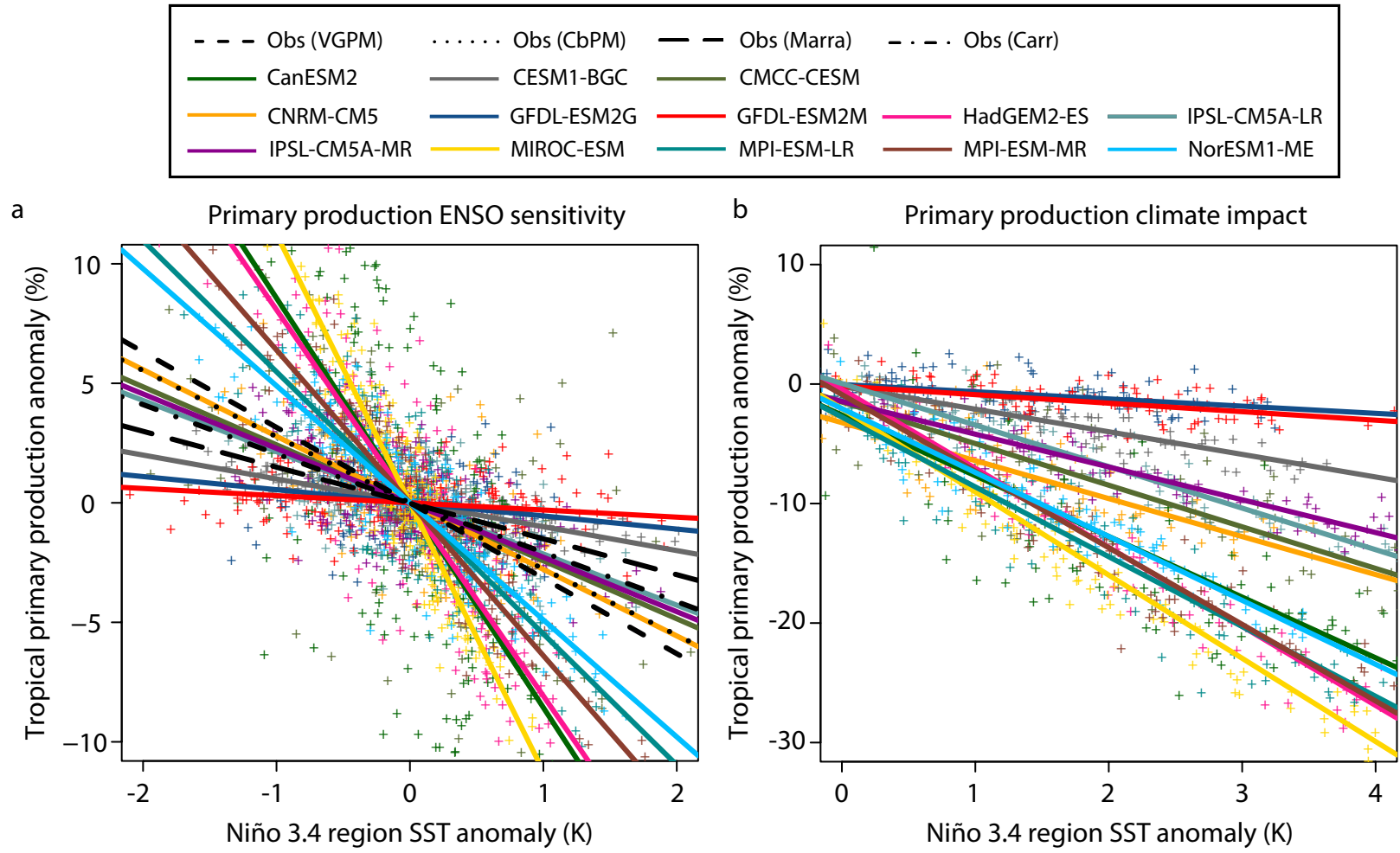

Figure 2. Primary production ENSO sensitivity and projected climate impact. a, The annual mean anomaly in tropical primary production against the annual mean Niño 3.4 region SST anomaly for CMIP5 pre-industrial control simulations (coloured lines) and observations (dashed black lines). $\mathbf{b}$, The annual mean anomaly in tropical primary production relative to 1990 s mean values against the annual mean Niño 3.4 region SST anomaly for CMIP5 RCP8.5 simulations. All linear regressions are significant at the $P$ $<0.05$ level. 
a
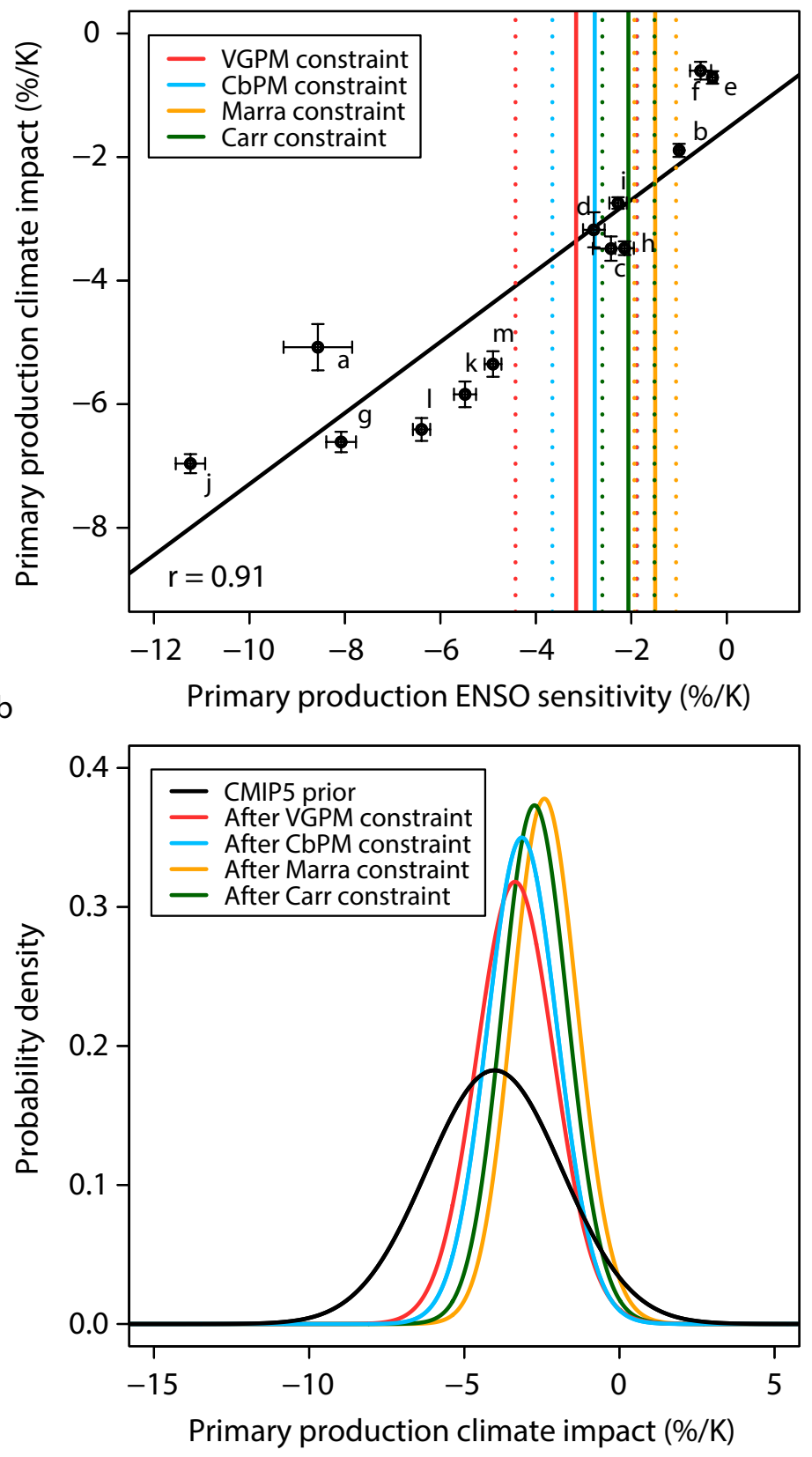

Figure 3. Emergent constraints on the sensitivity of tropical marine primary production to climate change. a, The long-term sensitivity of tropical primary production to Niño 3.4 region SST anomalies against the interannual sensitivity of tropical primary production to Niño 3.4 region SST anomalies. The best-fit observational constraints derived from the different primary production products are shown as solid vertical lines with dashed lines indicating \pm 1 standard error. $\mathbf{b}$, the probability density functions (PDFs) of the long-term SST sensitivity of tropical primary production. The black line shows the 'prior' PDF, assuming all models are equally likely and from a Gaussian distribution. The coloured lines show the four observationally constrained PDFs. 


\section{Methods}

\section{Earth System Models}

Depth integrated marine primary production model output was taken from the Coupled Model Intercomparison Project Phase 5 (CMIP5) ensemble of 13 ESMs that ran coupled ocean biogeochemistry schemes (Table S1). All models reached close to equilibrium NPP values prior to the last 200 years of pre-industrial control simulations. The sensitivity of multi-model emergent relationships to the future climate scenario and the NPP depth integral is shown in the supplementary information.

\section{Observational constraints}

To assess the sensitivity of results to the applied observational constraint, four net primary production estimates based on different remote sensing algorithms were used, the Vertically Generalised Production Model (VGPM) $)^{14}$, the Carbon-based Production Model (CbPM) ${ }^{28}$, the Marra et al. 2003 model (Marra $^{29}$ and the Carr et al. 2002 model (Carr) ${ }^{30}$. The VGPM, Carr and Marra algorithms all contain chlorophyll-specific carbon fixation efficiency terms that are a function of SST whereas the CbPM derives phytoplankton growth rates directly from satellite based carbon-to-chlorophyll ratios without using SST to characterise phytoplankton physiology.

The observed sensitivity of tropical primary production to SST anomalies in the Niño 3.4 region was diagnosed for the different NPP estimates using the contemporaneous HadISST ${ }^{31}$ SST record based on Advanced Very High Resolution Radiometer (AVHRR) measurements over the Sea-viewing Wide Field-ofView Sensor (SeaWIFS) satellite record (1998-2008; Fig. 2a, S6). The SeaWIFS record was used in order to encompass a major El Niño-La Niña transition during which there was large primary production

variability $^{20}$. A merged product of different satellite records was avoided to prevent any potential biases affecting observational constraints. The timescale of the observational records is such that they are dominated by ENSO variability and therefore unlike other studies (e.g. ${ }^{9}$ ), there is no need to remove a long-term climate signal by detrending.

\section{PDFs of long-term primary production sensitivity}

Probability density functions (PDFs) of the long-term SST sensitivity of tropical primary production were calculated for the unconstrained (prior) CMIP5 ensemble and the VGPM, CbPM, Marra and Carr emergent constraints. The prior PDF was derived assuming all models were equally likely and sampled from a Gaussian distribution. The constrained PDFs were calculated following previously established methodologies ${ }^{9}$. The PDFs of the VGPM, CbPM, Marra and Carr observational constraints are defined as:

$$
P(x)=\frac{1}{\sqrt{2 \pi \sigma_{x}^{2}}} \exp \left\{\frac{(x-\bar{x})^{2}}{2 \sigma_{x}^{2}}\right\}
$$

where $\bar{x}$ is the least-squares linear regression coefficient of NPP observations regressed against the Niño 3.4 region HadISST record and $\sigma_{x}$ is the corresponding standard error (Fig. S6). 
The 'prediction error' of the emergent multi-model linear regression $\left(\sigma_{f}(x)\right)$ defines contours of equal probability density around the multi-model linear regression, which represent the probability density of $y$ given $x$ :

$$
P(y \mid x)=\frac{1}{\sqrt{2 \pi \sigma_{f}^{2}}} \exp \left\{\frac{(y-f(x))^{2}}{2 \sigma_{f}^{2}}\right\}
$$

where $\sigma_{f}=\sigma_{f}(x)$.

Given the PDFs $P\{y \mid x\}$ and $P\{x\}$, the observationally constrained PDF for $y$ is:

$$
P(y) \int_{-\infty}^{\infty} P\{y \mid x\} P(x) d x
$$

Additional potential prior PDFs that weigh models based on their respective model family, ocean biogeochemistry scheme, or based on their relationship to observational PDFs are given in the supplementary material. All observationally constrained PDFs substantially reduce the uncertainty in projections of the long-term sensitivity of NPP relative to all potential prior PDFs (Fig. S7). As the longterm global primary production declines across the CMIP5 ensemble are driven by declines in the tropics ${ }^{4,25}$, the same approach can be utilised to constrain long-term projections of global NPP decline (Fig. S8).

\section{Data availability}

The data that support the findings of this paper are available from the author on request. All ESM model output is available via the Earth System Grid Federation (ESGF). 